Acta Crystallographica Section E

Structure Reports

Online

ISSN 1600-5368

\title{
[N, $N^{\prime}$-Bis(4-bromobenzylidene)-2,2-di- methylpropane- $\left.\kappa^{2} N, N^{\prime}\right]$ iodidocopper $(\mathrm{I})$. Corrigendum
}

\author{
Reza Kia, ${ }^{a}$ Hoong-Kun Fun ${ }^{\mathrm{a} *}$ and Hadi Kargar ${ }^{\mathrm{b}}$

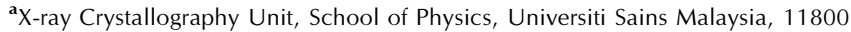 \\ USM, Penang, Malaysia, and ${ }^{\mathbf{b}}$ Department of Chemistry, School of Science, Payame \\ Noor University (PNU), Ardakan, Yazd, Iran \\ Correspondence e-mail: hkfun@usm.my
}

Received 16 June 2009; accepted 17 June 2009

The chemical name of the title compound in the paper by Kia, Fun \& Kargar [Acta Cryst. (2009), E65, m289] is corrected.

In the paper by Kia, Fun \& Kargar [Acta Cryst. (2009), E65, $\mathrm{m} 289]$, the chemical name given in the Title should be ' $\left[N, N^{\prime}\right.$ Bis(4-bromobenzylidene)-2,2-dimethylpropane-1,3-diamine$\left.\kappa^{2} N, N^{\prime}\right]$ iodidocopper(I)'. 